\title{
EM QUE MEDIDA O CARÁTER TÉCNICO-POLÍTICO DAS NORMAS EXPEDIDAS PELAS AGÊNCIAS REGULADORAS DETERMINA SUA NATUREZA JURÍDICA
}

\author{
Guilherme Francisco Paul* \\ João Gabriel Parmeggiani Pes**
}

\begin{abstract}
RESUMO: As Agências Reguladoras são dotadas de poder normativo específico, em face do fim especial a que se destinam, qual seja, intervenção em determinados setores econômicos. É grande a discussão doutrinária acerca da natureza jurídica das normas expedidas, destacando-se as correntes que defendem ser ato regulatório, ato administrativo normativo e ato regulamentar. Ainda não há posição jurisprudencial firme sobre o assunto. Através de uma abordagem lógico-dedutiva, demonstrar-se-á que a melhor definição sobre a natureza jurídica destas normas deve advir do caráter técnico e em particular do caráter político das normas expedidas e das Agências Reguladoras em si, bem como da efetividade esperada destas regras, e dos interesses sociais tocantes a estes entes autárquicos. Assim, levando em consideração essas características, a melhor definição é a de ato regulamentar.
\end{abstract}

PALAVRAS-CHAVE: Agências Reguladoras. Normas. Natureza Jurídica.

ABSTRACT: The Regulating Agencies are endowed with a specific normative power, in consequence of the special objective that it destines, that is, the intervention in determined economical sectors. There are a lot of doctrinal quarrels concerning the juridical nature of the norms edited by these agencies, detaching the defenders of normative power as regulatory act, as normative-administrative act, and as regulation acts. Still there is not a solid position on the subject. Beyond an logical-deductive approach, it will be demonstrated that the best definition concerning the juridical nature of these norms should become by the technical character and, particularly, the political character of the edited norms and of the Regulating Agencies themselves, as well as the effectiveness waited from those rules, and from the social interests pertaining to the these autarchic beings. Thus, adopting these characteristics, the better definition is that considers the referred norms like regulation act.

KEY WORDS: Regulating Agencies. Norms. Juridical Nature.

* Acadêmico do curso de Direito da Universidade Federal de Santa Maria

**Acadêmico do curso de Direito da Universidade Federal de Santa Maria

\section{INTRODUÇÃO:}

As Agências Reguladoras, inauguradas no Direito Brasileiro na segunda metade da década de 90 do século passado, têm o escopo de uma ingerir descentralizadamente na Economia, regulando serviços, inclusive públicos, bem como evitar e punir abusos por parte dos agentes de mercado e normatizar condutas a serem observadas por estes mesmos agentes. É uma seção da política hoje denominada Neoliberal.

Existem, ao todo, nove Agências com âmbito de atuação específico, definido em lei. São elas: Agência Nacional de Energia Elétrica - ANEEL -, Agência Nacional de Telecomunicações - ANATEL -, Agência Nacional do Petróleo - ANP -, Agência Nacional de Saúde - ANS -, Agência Nacional das Águas - ANA -, Agência Nacional de Vigilância Sanitária - ANVISA -, Agência Nacional de Transportes Terrestres ANTT -, Agência Nacional de Transportes Aquáticos -ANTAQ -, e Agência Nacional de Cinema - ANCINE -. 
Aportadas em nosso Direito como Autarquias especiais, vários são os destaques feitos na doutrina à função normativa técnica destes entes, e que em razão disso, a natureza jurídica das normas não ultrapassaria a de ato administrativo. No entanto, a celeuma é grande a este respeito, sendo causa geradora de inúmeros estudos por todo o país, não havendo, até o momento definição legal ou jurisprudencial definitiva sobre o tema.

O presente estudo tem por fim verificar a natureza técnica e também política que as normas editadas pelas Agências Reguladoras podem carrear. Desse modo, a classificação como ato normativo administrativo ou regulamento não adviriam unicamente do cunho cientificista da norma, pois teria de se atentar para a possibilidade da influência política determinar a natureza jurídica destas regras.

Através de uma abordagem lógico-dedutiva, principiaremos por analisar, de um modo geral, o caráter técnico e político das normas editadas, contrabalançando suas interferências em determinados setores econômicos, através da regulação dos serviços à que estão habilitadas. Em seguida traremos à discussão o entendimento de alguns doutrinadores sobre a natureza jurídica das normas editadas, apreciando-as como ato regulatório, ato administrativo normativo ou ainda ato regulamentar.

\section{O CARÁTER TÉCNICO-POLÍTICO DAS NORMAS}

\subsection{Da tecnicidade das normas}

Para analisar a tecnicidade ou cientificidade das normas editadas pelas Agências Reguladoras não é necessário grande esforço, pois inerente à função reguladora/regulamentar o conhecimento aprofundado acerca área em que atua a Agência.

Verdadeiramente, a autonomia técnica, dentre outras autonomias (financeira, administrativa, funcional), deferida às Agências não diverge dos elementos intrínsecos à natureza de toda e qualquer autarquia, como bem defende Celso Antônio Bandeira de Mello ${ }^{1}$. Destas óticas, não diferem as Agências das demais autarquias existentes no ordenamento jurídico brasileiro.

Mas a descentralização da ingerência estatal na Economia se dá, justamente, por esta ser cada vez mais dinâmica, complexa e especializada - catalisada pela transformação tecnológica e social - em seus diversos setores, impossibilitando a 
regulação diretamente pela Administração central do Estado, sem que se descuide de outros setores também carecedores zelo. Assim, não pode a ANEEL, por exemplo, regular e fiscalizar a produção, transmissão, distribuição e comercialização de energia elétrica caso não conheça as particularidades próprias deste setor econômico. Outrossim, não pode o Ministério de Minas e Energia despender suas atenções sem perder de vista outros projetos, como a ampliação da rede elétrica nacional.

De fato, é inimaginável que qualquer ente estatal, tendo poder de regular algum setor econômico, prescinda de alta especialização científica sobre o funcionamento dos agentes regulados, seus comportamentos e previsíveis atitudes futuras. O poder regulador conferido às Agências vem justamente do caráter destes entes que, ostentando certa eqüidistância quanto aos interesses da Administração e dos agentes de mercado, detêm a percepção lógico-racional do que é necessário à livre concorrência e respeito ao ordenamento jurídico, em especial aos consumidores.

Ademais, é possível verificar a imperiosidade técnica das Agências através dos requisitos de formação profissional ${ }^{2}$ que são exigidos legalmente para que alguém seja nomeado dirigente, contratado ou servidor dos entes em pauta.

Todavia, o caráter técnico das Agências Reguladoras não pode ser visto isoladamente, pois como adverte Alexandre Santos de Aragão ${ }^{3}$ :

[...]Não podemos, no entanto, ter a ingenuidade de achar que a tecnicidade é sempre acompanhada da imparcialidade, já que, salvo em casos limites, o saber técnico pode perfeitamente ser instrumentalizado em favor de diversos fins políticos.[...]

Com efeito, a concepção de que a ciência/técnica é imparcial, desprovida de qualquer ideologia, é falha. Muitas das normas editadas pelas Agências têm repercussão política, e esta repercussão é reflexo da ideologia das próprias Agências e seus diretores. Por isso a necessidade de estudar o caráter político destes atos normativos.

\subsection{Da repercussão política das normas}

Antes de analisar o caráter político das normas propriamente ditas, cabe lembrar que a influência política sobre as Agências Reguladoras é uma constante desde suas criações.

\footnotetext{
${ }^{2}$ A Lei 9.986/2000 exige formação superior e elevado conhecimento no campo de especialização, além de reputação ilibada. Agências como a ANP, ANEEL, ANVISA e ANA prevêem admissão temporária de pessoal técnico. E a Lei 10.871/2004 estabelece plano de carreiras e criação de cargos públicos com indispensável conhecimento sobre as áreas de atuação.

${ }^{3}$ ARAGÂO, Alexandre Santos de. Agências Reguladoras e a Evolução do Direito Administrativo Econômico. Ed. Forense, $2^{\mathrm{a}}$ Edição, pág. 324.
} 
É o que se observa quando considerada a indicação de seus dirigentes, pelo Presidente da República, após aprovação do Senado Federal ${ }^{4}$. A nomeação se dá para um mandato fixo, em geral de quatro anos, sendo reprimida a demissão imotivada. A fixidez do mandato não é garantida quando, em regra, houver condenação judicial transitada em julgado, processo administrativo disciplinar ou renúncia.

A indicação para os cargos de direção e gerência das Agências Reguladoras, como para demais cargos do "segundo escalão" da Administração Federal tem sido objeto de verdadeiras negociatas entre Governo e interessados, com o objetivo de formação de uma base aliada forte no Congresso Nacional para aprovar os projetos de lei de interesse do Poder Executivo. Assim, por si só já estaria configurada a característica política das Agências Reguladoras - sem desmerecer a capacidade técnica dos indicados - mas não se pode fechar os olhos ao modo como tem ocorrido a ascensão à tais cargos.

É possível notar política nas Agências também quando, em que pese as garantias conferidas a estes entes autárquicos - autonomia das mais variadas formas -, suas atuações não ultrapassam a esfera de competência dos Ministérios a que estão vinculadas, ou seja, estão submetidas às políticas públicas objetivadas pela Administração.

Isto se constata com clarividência da mera análise da Lei 9.472/97, instituidora da ANATEL, que em seu art. 19, I expõe que "À Agência compete (...)I - implementar, em sua esfera de atribuições, a política nacional de telecomunicações;;" (grifo nosso). O mesmo se pode dizer da Lei 9.427/96, instituidora da ANEEL, pois no art. $2^{\circ}$ consta que “(...) ANEEL tem por finalidade regular e fiscalizar a produção, transmissão, distribuição e comercialização de energia elétrica, em conformidade com as políticas e diretrizes do governo federal." (grifo nosso). Pode-se aferir o mesmo de todas as demais Agências, pois em suas leis instituidoras constam disposições semelhantes.

Ocorre que, logicamente, a política nacional dos serviços regulados, além da observância à Carta Maior, é comandada pelo Poder Executivo. Logo, as Agências que não tiverem em vista o desejado pela Administração podem ter sua autonomia, seja gerencial ou funcional relativizada, pois tal poder de ingerência é autorizado pelo art. 84, VI da Constituição Federal de 1988. Com efeito, este permissivo constitucional 
chancela a modificação de um departamento de um Ministério para uma Autarquia, e vice-versa, conforme Celso Antônio Bandeira de Mello ${ }^{5}$.

Quanto às normas editadas pelas Agências Reguladoras, para gerir determinados serviços, estas não são apenas técnicas. De fato, Hely Lopes Meirelles ${ }^{6}$, já considerava os atos administrativos como constitutivos de direitos, obrigações e sanções aos administrados. No mesmo sentido leciona Regis Fernandes de Oliveira, "que o mais simples ato administrativo praticado pela Administração Pública igualmente tem conteúdo político. "7

A título de ilustração, tomemos como exemplo a Resolução nº 477 da ANATEL, de 07 de agosto de 2007. Tal norma visa regulamentar o Serviço Móvel Pessoal ${ }^{8}$, instituindo verdadeiros direitos e deveres aos usuários e prestadoras (arts. $6^{\circ}-19$ ), além de dispor sobre o funcionamento de planos de serviços, preços a serem cobrados, prazos de permanência entre outras disposições.

Veja-se que o ato, mesmo que normativo e expedido por uma autarquia com poderes especiais, inova a ordem jurídica. Extrapola-se o conteúdo meramente técnico, que por definição deve ficar atrelado à lei, para discorrer sobre direitos e deveres. Ora, ressaltam as repercussões políticas, e mesmo jurídicas, destas disposições, pois tanto aqueles que se sentirem prejudicados poderão reclamar as garantias expostas na norma, quanto deverão, não só os usuários destes serviços, mas também a Administração e terceiros, atentar para as disposições ali contidas.

E assim ocorre com outros preceitos normativos, editados pelas Agências, como quando a ANEEL decide sobre penalidades a serem impostas aos concessionários, permissionários, autorizados, dos serviços de energia elétrica ${ }^{9}$, ou quando a ANATEL decide sobre algum modelo em particular de telefonia celular ou imagem digital dentre aqueles oferecidos no mercado externo. O mesmo raciocínio vale, inclusive, para decisões tomadas por outros entes que não Agências propriamente ditas, como o Conselho Monetário Nacional, ao decidir sobre a fixação da taxa de juros.

O que se pretende, com isso, é demonstrar que as normas expedidas pelas Agências não são somente técnicas, mas também eivadas de cargas jurídico-políticas. Mas estas, em regra, deveriam sempre observar os parâmetros ditados pela Administração central, sob pena de instaurar-se verdadeiro conflito de interesses.

\footnotetext{
${ }^{5}$ Ibid., pág. 324.

${ }^{6}$ MEIRELLES, Hely Lopes. Direito Administrativo Brasileiro. Ed. Malheiros. $32^{\text {a }}$ Ed., pág. 172.

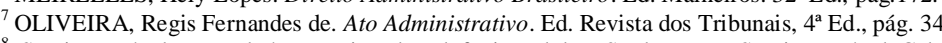

${ }^{8}$ Serviço Móvel Pessoal é o serviço de telefonia celular. Suplantou o Serviço Móvel Celular, trazendo vantagens para o consumidor, como a possibilidade de escolha da prestadora para ligações de longa distância (DDD) e maior controle das prestadoras desse serviço pela ANATEL.

${ }^{9}$ Resolução Normativa n ${ }^{\circ} 278$, de 11 de setembro de 2007 da ANEEL.
} 
Contudo, não é difícil de acontecer, por exemplo, de discordarem os dirigentes das Agências Reguladoras e o Presidente da República acerca de decisões a serem tomadas em determinado setor econômico. Nesta situação, a fim de dirimir as discussões sobre a permissividade legal das Agências Reguladoras ingerirem em matéria tradicionalmente de competência do Poder Executivo, é que se analisa a natureza jurídica das suas normas. E esta discussão será objeto de análise a seguir.

\section{NATUREZA JURÍDICA DAS NORMAS EXPEDIDAS}

\subsection{Natureza de atividade regulatória}

Em vista da já mencionada consecução de objetivos e finalidades públicas pelas Agências Reguladoras, é necessária a análise da natureza das normas por elas editadas, como acima já se ressaltou, para que se verifique, através de ótica legalista e paradigmática, se há adequação das normas aos fins a que se propõem tais autarquias.

Vê-se, na doutrina pátria, a adoção de três correntes para explicar o caráter nas normas editadas pelas Agências Reguladoras. São elas: natureza de atividade regulatória, natureza de regulamento e natureza de ato normativo-administrativo.

A primeira delas compara a atividade normativa das Agências Reguladoras com a atividade normativa primária, constante na Constituição Federal no art. 59. Ou seja, defende-se que essas autarquias especiais editem normas que se equiparam as espécies normativas decorrentes de processo legislativo, quais sejam emendas a Constituição, leis complementares, ordinárias e delegadas, medidas provisórias, decretos legislativos e resoluções.

Fundamenta-se tal teoria na possibilidade constitucional de delegação legislativa prevista no artigo 68 da Carta Magna, segundo o qual o Congresso Nacional poderá delegar ao Presidente a elaboração de leis. Segundo Henrique Ribeiro Cardoso ${ }^{10}$,

[...]Vislumbram os adeptos desta corrente estabelecer a Constituição Federal, no artigo que sedia a regulação em geral - art. 174, e nos que prevêem a criação das Agências Reguladoras - arts. 21 XI e 177, § $2^{\circ}$, III - uma atribuição originária de competência normativa, dentro do esquadro de repartição de funções estabelecidas na Carta Política, em moldes semelhantes ao disposto nos arts. 62 e 68 da Constituição de 1988.[...]

\footnotetext{
${ }^{10}$ CARDOSO, Henrique Ribeiro. O Poder Normativo das Agências Reguladoras. Rio de Janeiro. Lumen Júris. 2006. pg 199.
} 
Essa primeira tentativa de explicar o poder normativo das Agências Reguladoras deve ser logo rejeitada. Tal deve-se à clara aberração que se estaria criando ao considerar que uma autarquia fosse capaz de elaborar normas com status de lei sem que para isso fosse necessário um processo legislativo com aprovação de representantes populares, em total desrespeito a democracia, a separação de poderes e à legalidade.

Ainda, considera Henrique Ribeiro Cardoso ${ }^{11}$ que tal comparação não pode ser feita, pois somente a Constituição pode prever espécies normativas primárias, não sendo admitidas outras espécies por criação infraconstitucional. Quanto à pretensa atribuição de competência normativa, relata o autor que esta só é possível com expressa previsão constitucional, não sendo admitidas analogias.

Já em uma visualização prática, percebe-se ser necessária a recusa a tal entendimento em razão do excesso de poder que estaria concentrado nessas Agências. Ao considerar a natureza normativa dessas autarquias semelhante à lei, estar-se-ia dificultando o controle externo efetuado pelo Legislativo e também o controle interno efetuado pelo Executivo, vez que nem mesmo o Chefe do Executivo possui tamanho poder normativo.

\subsection{Natureza de ato administrativo normativo}

Os defensores dessa corrente, encabeçados por Maria Sylvia Zanella Di Pietro ${ }^{12}$, argumentam que as normas elaboradas pelas Agências Reguladoras têm natureza de ato administrativo geral, inferior ao regulamento e à lei. Ou seja, defendem que as normas editadas são aquelas inerentes aos órgãos administrativos, porém dotados de abstração e generalidade.

Fundamenta-se a conceituação do poder normativo como mero ato administrativo em virtude da imprevisão constitucional de entendimento contrário. Explica-se: em análise positivista ao texto constitucional, percebe-se não haver possibilidade de considerar o poder normativo das Agências Reguladoras com natureza de lei ou de regulamento, pois a primeira é prevista somente mediante processo legislativo pelo Congresso Nacional e o segundo está vinculado à atividade do Presidente da República. Assim, não resta outro entendimento senão o de que tal poder normativo é o mesmo concedido a qualquer outra entidade da administração direta ou indireta e que é hierarquicamente inferior à lei e ao regulamento.

\footnotetext{
${ }^{11}$ Ibid., p. 275

${ }^{12}$ DI PIETRO, Maria Sylvia Zanella. Direito Administrativo. São Paulo. 19 Edição. Atlas, 2006. p. 457. A autora define que a função normativa das Agências Reguladoras não pode ser maior do que a função comum a outro órgão da administração indireta sob pena de inconstitucionalidade, a exceção das Agências de Telecomunicações e do Petróleo, pois que previstas constitucionalmente e, por isso, dotadas de poder regulamentar.
} 
Portanto, decorre da adoção desta corrente, que os limites da atuação das Agências Reguladoras sejam mais rígidos, pois não há falar em inovação ao ordenamento jurídico, criação de direitos e obrigações não previstos em lei, somente em especificação, delimitação, explicitação e particularização de vocábulos contidos em lei. Esse é o entendimento de Maria Zanella Di Pietro ${ }^{13}$ e de Paulo Roberto Ferreira $\operatorname{Motta}^{14}$.

Contudo, para aqueles que defendem tal posicionamento, essa rigidez não configura prejuízo à função reguladora das Agências, por considerarem que não há necessidade de criação de direitos e deveres para tanto, pois a discricionariedade inerente aos atos administrativos irá possibilitar a adoção de soluções para a concretização dos fins definidos em lei.

Contudo, ao contrário do que pregam os defensores dessa corrente, os atos normativos das Agências não configuram meras delimitações e especificações de lei. Eles são, na realidade, dotados de capacidade normativa que supera os limites de atos administrativos gerais e abstratos, criando e vinculando direitos e obrigações.

É importante considerar ainda algumas conseqüências da adoção dessa corrente, tais como a facilidade de controle dos atos das Agências, tanto externamente, Legislativo e Judiciário (forma, competência e finalidade), quanto internamente, Executivo.

Pode-se dizer que embora seja razoável a adoção de tal corrente devido a uma ótica constitucional e de hierarquia legal, ela não encontra respaldo na realidade fática e, ainda, pragmaticamente, em vista da consecução dos objetivos reguladores, essa adoção não seria a mais eficaz.

Assim, para assegurar os interesses sociais e políticos, os quais representam a finalidade da atividade reguladora, são necessárias normas que tenham maior capacidade de vinculação, não podendo ficar somente adstritas a atos normativos dotados de discricionariedade técnica.

\subsection{Natureza de regulamento}

Para essa última teoria, a natureza do poder normativo das Agências Reguladoras é aquela proveniente dos regulamentos de competência do Chefe do Executivo. Para os defensores dessa corrente, portanto, os atos normativos editados

\footnotetext{
${ }^{13}$ Ibid. p. 462

${ }^{14}$ MOTTA, Paulo Roberto Ferreira. Agências Reguladoras. Barueri. Manole, 2003. p. 173.
} 
pelas agências, possuem a função de regulamentar a lei, tendo como base parâmetros e princípios, os quais não podem ser desrespeitados.

Hely Lopes Meirelles ${ }^{15}$, define regulamento com ato administrativo expedido pelo Chefe do Executivo, mediante decreto com a finalidade explicá-la, especificá-la e "prover sobre minúcias não abrangidas pela norma geral editada pelo Legislativo"16. Ressalta, entretanto que o regulamento não pode modificar a lei e se assim o fizer é considerado nulo.

O regulamento é hierarquicamente inferior à lei e superior aos atos administrativos de caráter geral. Não pode em seu conteúdo contrariar ou ampliar os limites do primeiro e, difere-se do segundo, pois é dotado de maior capacidade de produção de efeitos externos, vez que seus atos vinculam não somente a administração, mas também os particulares.

O fundamento para equiparar os atos das Agências Reguladoras com o regulamento de competência do Chefe do Executivo está presente na Constituição Federal, nos artigos 21, XI, 174 e 177, $\S 2^{\circ}$, III, os quais prevêem a criação de órgãos reguladores. Considera-se que há uma delegação, prevista na lei que criou as Agências, do poder regulamentar do Presidente da República para esses órgãos, já que estão realizando função administrativa de incumbência do Executivo. Ou seja, entende-se que o instrumento que prevê a criação de órgãos para cumprir uma função de controle, a qual deveria ser exercida pelo Executivo, prevê também a possibilidade de uso de recursos a ele pertencentes, tais como o regulamento.

Há que se mencionar ainda uma celeuma existente na consideração do ato normativo das Agências como ato regulamentar, qual seja, se há ou não inovação à ordem jurídica. Alguns autores defendem que não há inovação, ocorrendo apenas explicação e definição dos meios para executar a lei. Outros consideram que ocorre inovação, esta delimitada pelas leis que instituem as Agências, as quais concederiam liberdade para as decisões a serem tomadas mediante a observância das diretrizes e finalidades definidas em lei.

A adoção dessa última teoria traz algumas conseqüências de ordem práticas que não devem ser mitigadas. A primeira delas diz respeito a maior eficácia da atuação dos órgãos reguladores, pois as normas por elas editadas teriam maior caráter vinculativo, já

\footnotetext{
${ }^{15}$ MEIRELLES, Hely Lopes. Direito Administrativo Brasileiro. 32 ed., São Paulo: Malheiros, 2006. p.180 
que poderiam ser oponíveis a particulares e permitem maior liberdade de atuação das Agências na realização de seus objetivos.

Outra consequiência da adoção dessa corrente é o conflito de competência entre as Agências Reguladoras e eventual regulamento editado pelo próprio chefe do Executivo para um mesmo assunto. Nessa situação, entende Alexandre Santos de Aragão ${ }^{17}$, que não deve haver ingerência da Administração central no campo de atuação das Agências Reguladoras, devendo tanto uma quanto as outras respeitar a divisão de competência normativa feita pelo Legislador. Ademais, face à especialidade inerente à atuação das Agências, não pode ser outro o entendimento no sentido de tornar imprescindível sua atuação.

Assim, chega-se a um paradoxo na análise do caráter normativo das Agências Reguladoras. Enquanto a natureza de ato administrativo encontra uma melhor aceitação do ponto de vista legal e constitucional, ela não serve tão bem ao fim a que se destinam as Agências. O contrário ocorre com a natureza de regulamento, que embora não esteja expressamente prevista na Constituição, tem maior adequação à finalidade reguladora desses órgãos.

Portanto, com o fim de garantir maior efetividade às disposições das Agências Reguladoras, para melhor salvaguardar os interesses sociais objetos de sua atuação, tendo em vista ainda o eminente caráter político das decisões tomadas, a melhor conceituação da natureza dos poderes normativos das Agências Reguladoras é a de natureza regulamentar.

\section{CONSIDERAÇÕES FINAIS}

As Agências Reguladoras são autarquias especiais criadas com a finalidade de regular, controlar, e fiscalizar a prestação de serviço público, no intuito de salvaguardar os interesses da sociedade. Para o desempenho de tais funções, essas Agências gozam de independência administrativa, política, financeira e normativa.

Essa independência para atuação tem fundamento na complexidade da regulamentação nos diversos setores da economia e dela decorre que as Agências podem editar normas e/ou atos normativos para controlar as atividades de empresas privadas que exercem função pública.

Para exercer devidamente esse controle, as decisões das Agências Reguladoras, além do caráter técnico, se revestem de caráter político. Técnico no sentido de

\footnotetext{
${ }^{17}$ ARAGÃO, Alexandre Santos de. Agências Reguladoras e a Evolução do Direito Administrativo Econômico. Ed. Forense, $2^{\mathrm{a}}$ Edição,
} 
conhecimento específico sobre a área de atuação e de pormenorização de situações e procedimentos. Quanto ao caráter político, esse advém da necessidade de adequação às políticas públicas traçadas pela Administração, bem como pelo fato de propriamente exprimir normativamente a vontade da Administração.

Assim, o presente trabalho teve por objetivo definir a natureza dos atos normativos das Agências Reguladoras, levando em consideração a necessidade de expor tanto o caráter técnico, quanto o caráter político de sua atividade. Esse estudo mostra-se importante, pelo fato de existir grande divergência doutrinária e poucas decisões jurisprudenciais, decorrentes em parte por tratar-se de assunto novo no cenário jurídico pátrio.

Para tanto, foram apresentadas três teorias recorrentes na doutrina nacional que tentam explicar a natureza dos atos normativos e, através de uma análise tanto positivista quanto pragmática, buscou-se qual delas melhor se enquadra nessa situação.

Em análise individualizada a cada corrente doutrinária, viu-se que o ato normativo dos órgãos reguladores não possui natureza de lei, em virtude da falta de possibilidade formal, visto que somente o Poder Legislativo pode criar normas primárias. Quanto ao caráter de ato administrativo normativo, este foi negado, principalmente, em face da pouca efetividade que estes atribuiriam às Agências Reguladoras.

Dessa forma, restou caracterizado o caráter de regulamento como o que, tanto mediante a análise legal, quanto mediante a análise prática, apresentou melhores perspectivas de utilização para a consecução dos fins pretendidos pelas Agências Reguladoras. Isso ocorre, pois há possibilidade formal, através de delegação, de exercício de função regulamentar, bem como pela adequação desse instrumento para a necessidade de generalização, abstração, vinculação e respeito dos atos expedidos pelas Agências Reguladoras, em sua função de guardiãs especiais dos interesses sociais normatizados.

Em síntese pode-se dizer que, em virtude do eminente caráter político das normas editadas pelas Agências Reguladoras, percebe-se que estas têm natureza de regulamento.

Contudo, tal conclusão não encerra o assunto, apenas dá as coordenadas para muitas outras discussões que serão travadas a esse respeito. Tem-se o exemplo de como deve ser o controle das Agências Reguladoras, em que medida ingerências da 
Administração Central podem afetar seu funcionamento e outras mais que devem ser objeto de estudos futuros.

\section{REFERÊNCIAS BIBLIOGRÁFICAS}

ARAGÃO, Alexandre Santos de. Agências Reguladoras e a Evolução do Direito Administrativo Econômico. $2^{\text {a }}$ Edição. Rio de Janeiro. Forense. 2005.

BRASIL. Constituição da República Federativa do Brasil: promulgada em 05 de outubro de 1988. Atualizada até a Emenda Constitucional n ${ }^{\circ}$ 53, de 19/12/2006. $9^{a}$ ed. São Paulo: Revista dos Tribunais, 2007.

BRASIL. Lei 9.427, publicada em 26 de dezembro de 1996. $6^{\text {a }}$ ed. São Paulo: Revista dos Tribunais, 2006.

BRASIL. Lei 9.472, publicada em 16 de julho de 1997. $6^{\text {a }}$ ed. São Paulo: Revista dos Tribunais, 2006.

BRASIL. Lei 9.478, publicada em 07 de agosto de 1997. $6^{\text {a }}$ ed. São Paulo: Revista dos Tribunais, 2006.

BRASIL. Lei 9.782, publicada em 27 de janeiro de 1999. 6a ed. São Paulo: Revista dos Tribunais, 2006.

BRASIL. Lei 9.961, publicada em 29 de janeiro de 2000. $6^{\text {a }}$ ed. São Paulo: Revista dos Tribunais, 2006.

BRASIL. Lei 9.984, publicada em 18 de julho de 2000. $6^{\text {a }}$ ed. São Paulo: Revista dos Tribunais, 2006.

BRASIL. Lei 9.986, publicada em 19 de julho de 2000. $6^{\text {a }}$ ed. São Paulo: Revista dos Tribunais, 2006.

BRASIL. Lei 10.233, publicada em 06 de junho de 2001. $6^{\text {a }}$ ed. São Paulo: Revista dos Tribunais, 2006.

BRASIL. Medida Provisória $n^{\circ}$ 2.228, publicada em 10 de setembro de 2001. www.planalto.gov.br.

BRASIL. Lei 10.871, publicada em 20 de maio de 2004. www.planalto.gov.br.

BRASIL. Resolução $\mathrm{n}^{\circ} 477$ da ANATEL, publicada em 07 de agosto de 2007. www.anatel.gov.br.

BRASIL. Resolução no 278 da ANEEL, publicada em 11 de setembro de 2007. www.aneel.gov.br.

CARDOSO, Henrique Ribeiro. O Poder Normativo das Agências Reguladoras. Rio de Janeiro. Lumen Júris. 2006

DI PIETRO, Maria Sylvia Zanella. Direito Administrativo. São Paulo. 19 Edição. Atlas, 2006

MEIRELLES, Hely Lopes. Direito Administrativo Brasileiro. $32^{\text {a }}$ Edição. São Paulo. Malheiros. 2006.

MELlO, Celso Antônio Bandeira de. Curso de Direito Administrativo. $21^{\text {a }}$ Edição. São Paulo. Malheiros. 2006.

MOTTA, Paulo Roberto Ferreira. Agências Reguladoras. Barueri. Manole, 2003

OLIVEIRA, Regis Fernandes de. Ato Administrativo. 4 ${ }^{a}$ Edição. São Paulo. Revista dos Tribunais. 2001. 
